OPEN ACCESS

Edited by:

Guihua Wang,

Fudan University, China

Reviewed by:

Ernesto Dos Santos Caetano Neto,

National Autonomous University of

Mexico, Mexico

Huaji Pang,

Qingdao Meteorological Bureau,

China

*Correspondence:

Chunlei Liu

liuclei@gdou.edu.cn

Hongfei Mao

Maohf@gdou.edu.cn

Yufeng Xue

xueyf@gdou.edu.cn

Specialty section:

This article was submitted to

Atmospheric Science,

a section of the journal

Frontiers in Earth Science

Received: 09 June 2021 Accepted: 28 September 2021

Published: 18 October 2021

Citation:

Zhang S, Liu C, Xu J, Zhang S, Tang R, Huang Z, Zheng Y, Guan Z, Mao H and

Xue $Y$ (2021) Physical Process

Contributions to the Development of a

Super Explosive Cyclone Over the

Gulf Stream.

Front. Earth Sci. 9:722555

doi: 10.3389/feart.2021.722555

\section{Physical Process Contributions to the Development of a Super Explosive Cyclone Over the Gulf Stream}

\author{
Shuqin Zhang ${ }^{1,2,3,4}$, Chunlei Liu ${ }^{2,4 *}$, Jianjun $X u^{2,4}$, Shaojing Zhang ${ }^{1,2}$, Ruoying Tang ${ }^{5}$, \\ Zhefan Huang ${ }^{1}$, Yanzhu Zheng ${ }^{1}$, Zhuoqiang Guan ${ }^{1}$, Hongfei Mao ${ }^{6 *}$ and Yufeng Xue ${ }^{1,2,3,4 *}$ \\ ${ }^{1}$ College of Ocean and Meteorology, Guangdong Ocean University, Zhanjiang, China, ${ }^{2}$ South China Sea Institute of Marine \\ Meteorology, Guangdong Ocean University, Zhanjiang, China, ${ }^{3}$ Key Laboratory of Climate, Resources and Environment in \\ Continental Shelf Sea and Deep Sea of Department of Education of Guangdong Province, Guangdong Ocean University, \\ Zhanjiang, China, ${ }^{4}$ CMA-GDOU Joint Laboratory for Marine Meteorology, Zhanjiang, China, ${ }^{5}$ College of Coastal Agricultural \\ Sciences, Guangdong Ocean University, Zhanjiang, China, ${ }^{6}$ College of Ocean Engineering, Guangdong Ocean University, \\ Zhanjiang, China
}

Contributions of different physical processes to the development of a super explosive cyclone (SEC) migrating over the Gulf Stream with the maximum deepening rate of 3.45 Bergeron were investigated using the ERA5 atmospheric reanalysis from European Centre for Medium-Range Weather Forecasts (ECMWF). The evolution of the SEC resembled the Shapiro-Keyser model. The moisture transported to the bent-back front by easterlies from Gulf Stream favored precipitation and enhanced the latent heat release. The bent-back front and warm front were dominated by the water vapor convergence in the mid-low troposphere, the cyclonic-vorticity advection in the midupper troposphere and the divergence in the upper troposphere. These factors favored the rapid development of the SEC, but their contributions showed significant differences during the explosive-developing stage. The diagnostic results based on the Zwack-Okossi equation suggested that the early explosive development of the SEC was mainly forced by the diabatic heating in the mid-low troposphere. From the early explosive-developing moment to maximum-deepening-rate moment, the diabatic heating, warm-air advection and cyclonic-vorticity advection were all enhanced significantly, their combination forced the most explosive development, and the diabatic heating had the biggest contribution, followed by the warm-air advection and cyclonic-vorticity advection, which is different from the previous studies of ECs over the Northwestern Atlantic. The cross section of these factors suggested that during the rapid development, the cyclonic-vorticity advection was distributed and enhanced significantly in the mid-low troposphere, the warm-air advection was strengthened significantly in the mid-low and upper troposphere, and the diabatic heating was distributed in the middle troposphere.

Keywords: super explosive cyclone, Gulf Stream, structure, diagnostic analysis, physical process 


\section{INTRODUCTION}

It has been observed that the extratropical cyclones can develop explosively by a rapid drop of the sea level pressure (SLP) at the center and a sharp enhancement of the intensity within a very short time. Rice (1979) called them Meteorological bombs and they are one of the most dangerous weather systems in winter over the mid-latitude oceans, with 2-5 days lifespan and 2,000-3,000 km horizontal scales, leading to extremely severe winds and heavy precipitation and potentially causing serious losses of life and property (Liberato et al., 2011; Liberato et al., 2013). Sanders and Gyakum (1980) defined the explosive cyclone (EC) as the one with the central SLP drops more than $24 \mathrm{hPa}$ within $24 \mathrm{~h}$ when adjusted geostrophically to $60^{\circ} \mathrm{N}$. The latitude adjustment is performed to account for the variation of the geostrophic wind with latitude for a given pressure gradient. Given the facts that ECs usually occur in the mid-latitude and that the high-resolution reanalysis data are widely used, Zhang et al. (2017) adjusted the latitude to $45^{\circ} \mathrm{N}$ and set the pressure fall to $12 \mathrm{hPa} / 12 \mathrm{~h}$. The one "Bergeron" of a $24 \mathrm{hPa} / 24 \mathrm{~h}$ at $60^{\circ} \mathrm{N}$ in Sanders and Gyakum (1980) was modified into a $12 \mathrm{hPa} / 12 \mathrm{~h}$ at $45^{\circ} \mathrm{N}$. In addition, these ECs were classified into four categories using K-means clustering algorithm based on the maximum deepening rate: Super ( $\geq 2.30$ Bergeron), strong (1.70-2.29 Bergeron), moderate (1.30-1.69 Bergeron) and weak (1.00-1.29 Bergeron).

In the Northern Hemisphere, ECs occurred frequently over the Northwestern Pacific and the Northwestern Atlantic (Rogers and Bosart, 1986; Lim and Simmonds, 2002; Iwao et al., 2012; Zhang et al., 2017; Fu et al., 2020), especially over the Gulf Stream and Kuroshio/Kuroshio Extension regions (Roebber, 1984; Gyakum et al., 1989; Wang and Rogers, 2001; Allen et al., 2010; Seiler and Zwiers, 2016a, 2016b). The Gulf Stream and Kuroshio/ Kuroshio Extension supply abundant moisture and turbulent (sensible and latent) heat fluxes, which favor the rapid development of ECs through increasing the latent heat release and decreasing atmospheric stability (Nuss and Kamikawa 1990; Kuo et al., 1991b; Reed et al., 1993b; Neiman and Shapiro 1993; Takayabu et al., 1996; Booth et al., 2012). Based on the frequency spatial distribution of the maximum-deepening-rate position, Wang and Rogers (2001) classified ECs over the North Atlantic into three types: NWA (Northwest Atlantic), NCA (North-Central Atlantic) and NEA (Northeast Atlantic), and the high frequency center over NWA near the Gulf Stream was the strongest (Sun et al., 2018). Allen et al. (2010) compared the distribution of ECs using NCEP2 (the second National Centers for Environmental Prediction), JRA (the Japanese Reanalysis) and ECMWF (European Centre for MediumRange Weather Forecasts) data with different spatial resolutions from 1979 to 2008, and they obtained similar results with those of Wang and Rogers (2001). Sanders and Gyakum (1980) indicated that the monthly frequency of ECs peaked in January and November over the Northern Hemisphere, while it peaked in February over NWA. Sun et al. (2018) suggested that the seasonal variation characteristics of the EC frequency in different regions of the Northern Atlantic showed significant differences.

Four famous ECs over the Northwestern Atlantic have been extensively investigated in the previous studies, including the Queen Elizabeth II storm in 1978 (Gyakum, 1983a, 1983b, 1991; Anthes et al., 1983; Manobianco, 1989), the President Day's Cyclone in 1979 (Bosart, 1981; Bosart and Lin, 1984; Uccellini et al., 1984, 1985; Whitaker et al., 1988), the ERICA IOP-4 Cyclone in 1989 (Wakimoto et al., 1992; Chang et al., 1993, 1996; Neiman et al., 1993; Neiman and Shapiro, 1993; Rausch and Smith, 1996), and the ERICA IOP-5 Cyclone in 1989 (Reed et al., 1993a, 1993b; Blier and Wakimoto, 1995; Kuo et al., 1996). Several mechanisms of EC development were suggested, such as the baroclinic instability (Sanders and Gyakum, 1980; Bosart, 1981; Manobianco, 1989; Wang and Rogers, 2001), diabatic heating (Gyakum, 1983b; Kuo et al., 1991a; Stoelinga, 1996; Moore et al., 2008; Willison et al., 2013), upper-level forcing (Bosart and Lin, 1984; Sanders, 1986; Gyakum, 1991), upper-level jet stream (Uccellini et al., 1984; Manobianco, 1989), intrusion of high potential vorticity (PV) air (Bosart and Lin, 1984; Uccellini et al., 1985; Whitaker et al., 1988; Davis and Emanuel, 1991; Reed et al., 1992), and multiple factors (Rausch and Smith, 1996; Nesterov, 2010). Lupo et al. (1992) used the Zwack-Okossi (Z-O) equation to examine ECs over the Gulf Stream off the coast of New England, near the location of the four famous cases over the Northwestern Atlantic, and the results revealed that the contribution of the diabatic heating was important but generally smaller than that of the cyclonic-vorticity advection and warm-air advection. Using the composite analysis Sanders (1986) and Wang and Rogers (2001) pointed out that ECs over the Northwestern Atlantic tended to have strong baroclinicity, consistent with the results from the four famous cases over the Northwestern Atlantic (Bosart, 1981; Gyakum, 1983a, 1983b; Anthes et al., 1983; Manobianco, 1989).

The Gulf Stream, known as the warm current in the North Atlantic flowing from the Gulf of Mexico northeast along the United States coast to Nantucket and from there eastward, is an important region for the global navigation associated with the frequent commercial and economic activities. The EC occurs frequently near the Gulf Stream (Sun et al., 2018) and is one of the most dangerous weather systems over this area. Some ECs around this area have been studied, but the extreme EC over the Gulf Stream has been rarely investigated and its development mechanism is still not clear. In this study, a super EC (SEC) migrating over the Gulf Stream $\left(27-58^{\circ} \mathrm{N}, 79-49^{\circ} \mathrm{W}\right)$ from 25 to March 29, 2014 was studied. It is the most explosive development case during the last 20 years, causing serious economic losses, for example, more than 2,500 flights were delayed and 415 flights were canceled in America. Traffics were severely blocked due to the heavy snow associated with the SEC and many buildings were damaged by the severe wind. To reveal the development processes of this SEC, the atmospheric environment and structure are investigated, and the dynamic and thermodynamic factors such as the vorticity advection, temperature advection and diabatic 
heating are diagnosed quantitatively based on the $\mathrm{Z}-\mathrm{O}$ equation using ERA5 atmospheric reanalysis from ECMWF (Hersbach et al., 2020). The data and methods are described in Data and Methods, the evolution and synoptic-scale atmospheric environment of the SEC are in Synoptic Study. Diagnostic Results presents the results from the Z-O equation and the last section is the Discussion and Conclusion.

\section{DATA AND METHODS}

\section{Data}

The hourly variables such as the geopotential height, horizontal wind, vertical velocity, temperature, relative humidity and SLP are from ERA5 data provided by ECMWF. ERA5 data are produced using 4D-Var data assimilation in CY41R2 of ECMWF's Integrated Forecast System (IFS) (Hersbach et al., 2020). The ERA5 data are downloaded with $0.25^{\circ} \times 0.25^{\circ}$ horizontal resolution and 37 vertical levels from 1,000 to $1 \mathrm{hPa}$ (all layers in hPa: $1,000,975$, $950,925,900,875,850,825,800,775,750,700,650,600,550$, $500,450,400,350,300,250,225,200,175,150,125,100,70,50$, $30,20,10,7,5,3,2$ and 1$)$. They are used to examine the atmospheric environment variation and for the diagnostic analysis to reveal the physical process contributions to the development of the SEC.

\section{Methods}

\section{Definition of EC}

The EC definition modified by Zhang et al. (2017) is used in this study and the deepening rate (DR in Bergeron) of a cyclone SLP can be calculated using the following formula:

$$
\mathrm{DR}=\left[\frac{\mathrm{P}_{t-6}-\mathrm{P}_{t+6}}{12}\right] \times\left[\frac{\sin 45^{\circ}}{\sin \frac{\varphi_{t-6}+\varphi_{t+6}}{2}}\right]
$$

where $t$ is the analyzed time in hour. $P$ is the central SLP, and $\varphi$ is the latitude of the cyclone center defined as the minimum SLP position. Subscripts " $t-6$ " and " $t+6$ " represent the time of $6 \mathrm{~h}$ before and after the time $t$, respectively. The EC is defined as the cyclone with the DR greater than or equal to 1 Bergeron.

\section{Z-O Equation}

The Z-O equation originally derived by Zwack and Okossi (1986) by integrating the omega equation was in quasigeostrophic form. It is further developed by Lupo et al. (1992) in a generalized form by substituting the hydrostatic balance equation, state equation, and the first law of thermodynamics into the equation. Moreover, the generalized form of the Z-O equation is simplified by removing some small terms in order to avoid aliasing errors (Lupo et al., 1992). It has been demonstrated that the simplified $\mathrm{Z}$-O equation is an effective tool for diagnosing synoptic-scale development of the EC and it has been successfully applied to many studies (Morris and Smith, 2001; Strahl and Smith, 2001;
Yoshida and Asuma, 2004; Azad and Sorteberg, 2014). The simplified $\mathrm{Z}-\mathrm{O}$ equation can be written as:

$$
\frac{\partial \zeta_{g l}}{\partial t}=\frac{1}{P_{l}-P_{t}} \int_{P_{t}}^{P_{t}}-\vec{V} \cdot \nabla \zeta_{a} d P-\frac{1}{P_{l}-P_{t}} \int_{P_{t}}^{P_{t}}\left[\frac{R}{f} \int_{P}^{P_{t}} \nabla^{2}\left(-\vec{V} \cdot \nabla T+\frac{\dot{Q}}{C_{p}}+S \omega\right) d \ln P\right] d P
$$

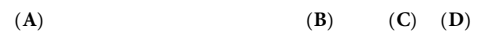

where $\zeta_{g l}$ is the geostrophic vorticity at the lower boundary, $\zeta_{a}$ is the absolute vorticity, $P_{l}$ is the pressure at the lower boundary, $P_{t}$ is the pressure at the upper boundary, $\vec{V}$ is the horizontal wind velocity, $\omega$ is the vertical velocity in isobaric coordinates, $C_{p}$ is the specific heat at constant pressure, $S$ is the static stability parameter ( $S=-\frac{T}{\theta} \frac{\partial \theta}{\partial P}$ and $\theta$ is the potential temperature), $\dot{Q}$ is the diabatic heating rate $\left(\dot{Q}=C_{p}\left(\frac{\partial T}{\partial t}+\vec{V} \cdot \nabla T-S \omega\right)\right)$ calculated by the thermodynamic energy equation (Holton, 2004), $R$ is the dry air gas constant, $f$ is the Coriolis force parameter and $T$ is the temperature. Term A $\left(\frac{1}{P_{l}-P_{t}} \int_{P_{t}}^{P_{l}}-\vec{V} \cdot \nabla \zeta_{a} d P\right)$ reflects the contribution of the absolute horizontal vorticity advection to the near-surface geostrophic vorticity tendency. Term B $\left(-\frac{1}{P_{l}-P_{t}} \int_{P_{t}}^{P_{l}}\left[\frac{R}{f} \int_{P}^{P_{l}} \nabla^{2}(-\vec{V} \cdot \nabla T) d \ln P\right] d P\right)$ describes the effect of the horizontal temperature advection and term $\mathrm{C}$ $\left(-\frac{1}{P_{l}-P_{t}} \int_{P_{t}}^{P_{l}}\left[\frac{R}{f} \int_{P}^{P_{l}} \nabla^{2}\left(\frac{\dot{Q}}{C_{p}}\right) d \ln P\right] d P\right)$ represents the diabatic heating and cooling. Term D $\left(-\frac{1}{P_{l}-P_{t}} \int_{P_{t}}^{P_{l}}\left[\frac{R}{f} \int_{P}^{P_{l}} \nabla^{2}(S \omega) d \ln P\right] d P\right)$ is the effect of the adiabatic temperature change due to the vertical motion. The cyclonic-vorticity advection forces to generate the vertical secondary circulation by increasing the local vorticity, which strengthens the near-surface convergence and geostrophic vorticity. The warm-air advection increases the geopotential height of upper-level ridge and results in the increase of the near-surface convergence and geostrophic vorticity. The diabatic heating due to the latent heat release enhances the ascending motion and favors the near-surface convergence.

Each term in the Z-O equation is calculated using the ERA5 data and a second-order finite-difference method is used to calculate the horizontal and vertical derivatives. The trapezoidal rule is used to estimate the vertical integrals. Based on Lupo et al. (1992) and Rausch and Smith (1996), the $950 \mathrm{hPa}$ and $100 \mathrm{hPa}$ are chosen as $P_{l}$ and $P_{t}$, respectively, since the $950 \mathrm{hPa}$ is an isobaric level above the ground and sufficiently close to the surface to be representative of the surface cyclogenesis and $100 \mathrm{hPa}$ is a sufficient high level containing the whole troposphere. There are 23 levels between $950 \mathrm{hPa}$ and $100 \mathrm{hPa}$. To reduce the subsynoptic-scale noise, each term is smoothed by the two-dimensional second-order filtering scheme (Shapiro, 1970).

To explore the role of the individual forcing process at different pressure levels in the Z-O equation, Rausch and Smith (1996) constructed the vertical profiles of each forcing term in Equation 2. As the vertical interval $(\Delta \mathrm{P})$ between pressure 

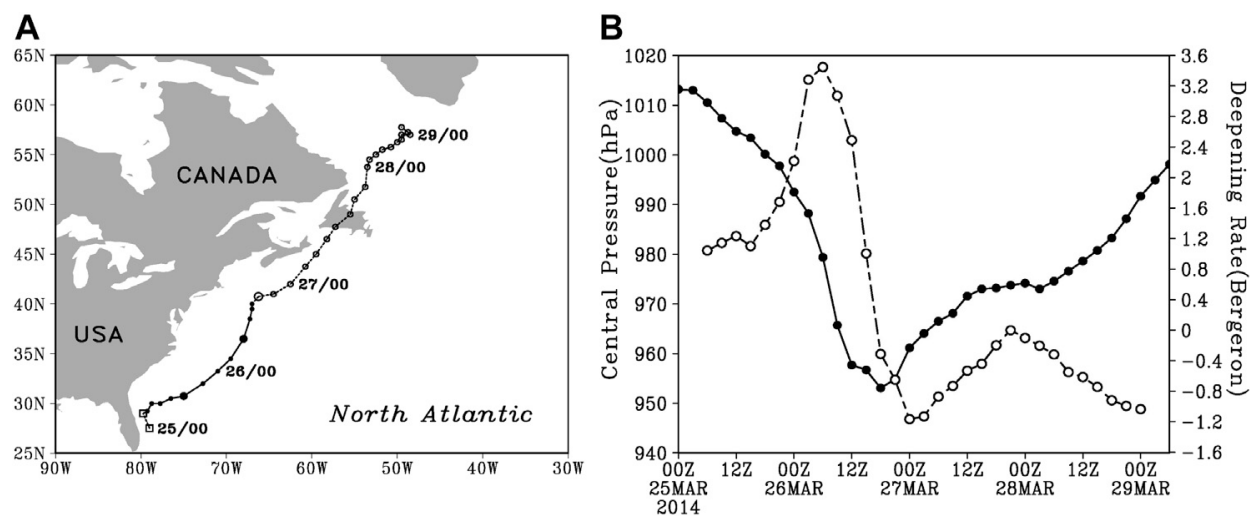

FIGURE 1 | (A) The moving track (3-h intervals), and (B) the time series of the central SLP (solid, in hPa) and deepening rate (dashed, in Bergeron). EC center is defined as the minimum SLP position.

levels varies in ERA5 data, the method of Rausch and Smith (1996) is modified and each of the thermodynamic terms (terms B, C and D) in Equation 2 can be profiled by the following formula.

$$
F_{n}=-\frac{R}{f\left(p_{l}-p_{N}\right)}\left[\begin{array}{l}
\frac{H_{1}}{4} \Delta P_{1}\left(P_{N-1}-P_{1}\right), n=1 \\
\left(\frac{H_{n}}{4}\right)\left[\left(P_{n+1}^{2}-P_{n-1}^{2}+2 P_{0}\left(P_{n-1}-P_{n+1}\right)\right]\right), 2 \leq n \leq N-1 \\
\left(\frac{H_{N}}{4} \Delta P_{N-1}\right)\left(\Delta P_{N-1}\right), n=N
\end{array}\right]
$$

where $P_{l}$ and $P_{N}$ are air pressure at the first and Nth levels, respectively, $\Delta P_{n}=P_{n+1}-P_{n}, H_{n}$ represents $-\vec{V} \cdot \nabla T, \frac{Q}{C_{p}}$ or $S \omega$ in Equation 2.

Referring to Equation 2, the contribution of the dynamic term (term A) at each level can be profiled using the following formula:

$$
F_{n}=-\frac{R}{f\left(p_{l}-p_{N}\right)}\left[\begin{array}{l}
\left(\frac{I_{1}}{2}\right)\left(\Delta p_{1}\right), n=1 \\
\left(\frac{I_{n}}{2}\right)\left(\Delta p_{n-1}+\Delta p_{n}\right), 2 \leq n \leq N-1 \\
\left(\frac{I_{N}}{2}\right) \Delta p_{N-1}, n=N
\end{array}\right]
$$

where $I_{n}$ is the dynamic term $-\vec{V} \cdot \nabla \zeta_{a}$ (term A). This updated method of constructing the profile can be applied to data with any vertical resolution.

\section{Eady Growth Rate Equation}

The EC over the warm current will be strongly influenced by the moisture. Considering the impact of the latent heat release on the baroclinicity through changes in the vertical stability term, the Eady growth rate (Eady, 1949; Hoskins and Valdes, 1990) is taken as the measure of baroclinicity and can be written as

$$
\sigma=0.31\left(\frac{f}{N}\right)\left|\frac{\partial V}{\partial z}\right|
$$

where $f$ is the Coriolis parameter, $N$ is the Brunt-Väisälä frequency and $V$ is the horizontal wind speed.

\section{SYNOPTIC STUDY}

\section{SEC Evolution}

The most rapid development EC over the Gulf Stream during the last 20 years occurred from 00 UTC 25 to 06 UTC March 29, 2014 with the northeastward moving track (Figure 1A). The maximum deepening rate reached 3.45 Bergeron and the central SLP dropped to the minimum of $953.1 \mathrm{hPa}$ during its lifetime (Figure 1B). It was formed over the eastern sea of Florida $\left(27.5^{\circ} \mathrm{N}, 79^{\circ} \mathrm{W}\right)$ at $00 \mathrm{UTC}$ March 25, 2014 with a central SLP of $1,012.1 \mathrm{hPa}$ (Figure 1). It started the explosive development with the deepening rate of 1.04 Bergeron at 06 UTC 25 (Figure 1B). The deepening rate increased dramatically with the rapid drop of the central SLP after 18 UTC 25 (Figure 1B). At 06 UTC 26 over the eastern sea of North Carolina $\left(36.5^{\circ} \mathrm{N}, 68^{\circ} \mathrm{W}\right)$, it experienced the most rapid development with the maximum deepening rate of 3.45 Bergeron and the central SLP drop of $34.8 \mathrm{hPa}$ in $12 \mathrm{~h}$. The explosive-developing stage with the deepening rate more than 1 Bergeron lasted $33 \mathrm{~h}$ from 06 UTC 25 to 15 UTC March 26, 2014. The development of the SEC slowed down with the deepening rate of central SLP less than 1 Bergeron after 18 UTC 26, which fell to the minimum SLP of $953.1 \mathrm{hPa}$ at 00 UTC 27. It finally disappeared over the eastern coast of Canada $\left(57.75^{\circ} \mathrm{N}, 49.5^{\circ} \mathrm{W}\right)$ in Newfoundland at 06 UTC 29.

The evolution of the SLP, precipitation, wind and $0^{\circ}$ temperature at $2 \mathrm{~m}$ from 12 UTC 25 to 18 UTC March 26, 2014 are shown in Figure 2. At 12 UTC 25 (Figure 2A), the precipitation was distributed to the north and southeast of the SEC center, the wind speed was less than $12 \mathrm{~m} / \mathrm{s}$. The $0^{\circ}$ temperature showed approximately a straight line to the north of the SEC. The anticyclones over the North American and the North Atlantic Ocean existed to the northwest and northeast of the SEC, respectively. From 18 UTC 25 to 00 UTC 26 (Figures $2 \mathbf{B}, \mathbf{C})$, the precipitation area increased significantly. The northwestern anticyclone intruded from the northwest of the SEC and northeastern anticyclone strengthened gradually, resulting in the northwestern and southeastern gales to appear at 00 UTC 26. From 00 UTC 26 to 06 UTC 26, the precipitation 

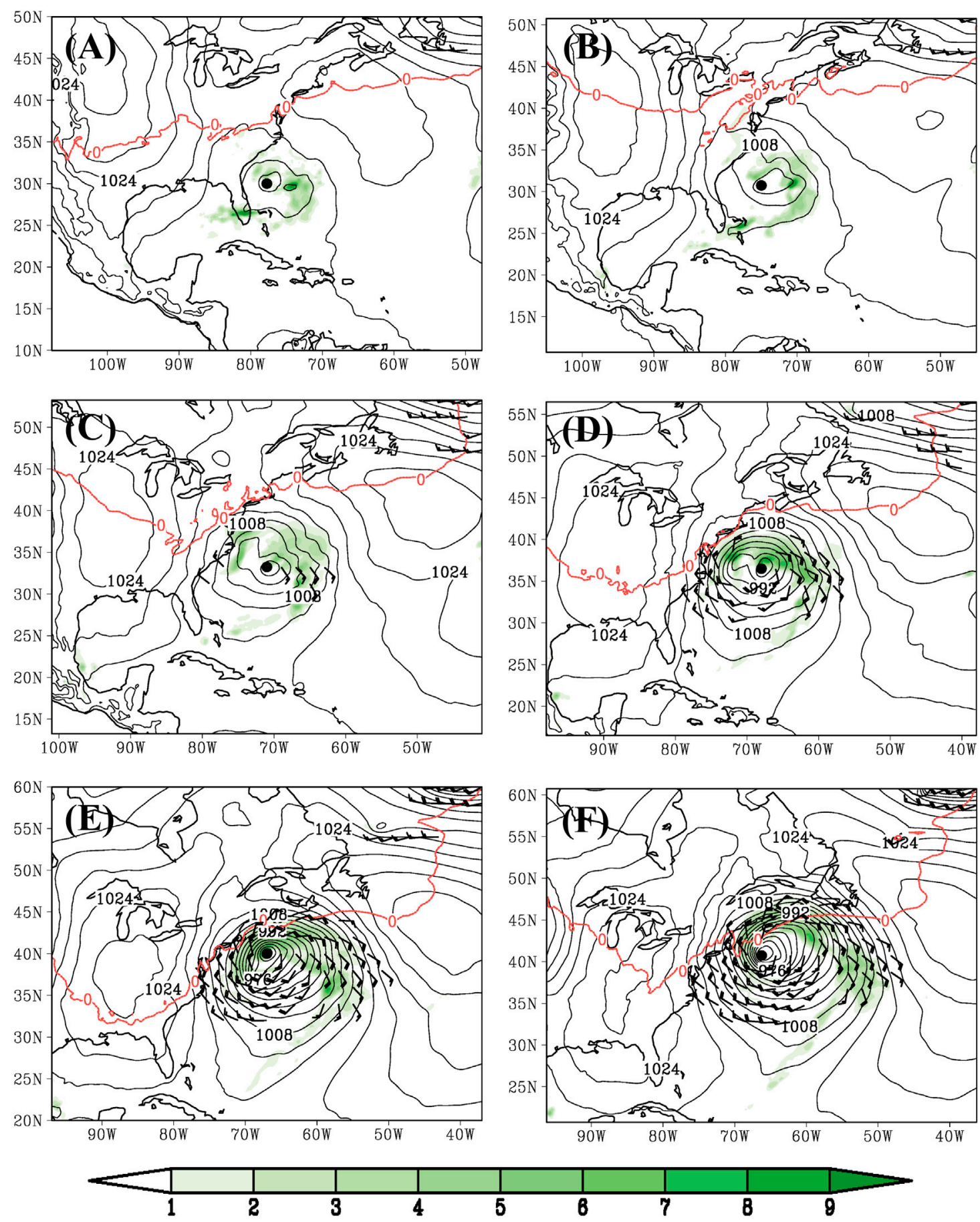

FIGURE 2 | Sea level pressure (solid, 4 hPa intervals), 1-h accumulated precipitation (shaded, 1 mm intervals), gale (bard, $\geq 12 \mathrm{~m} \mathrm{~s}{ }^{-1}$ ) and $0^{\circ}$ temperature at $2 \mathrm{~m}$ (red) at (A) 12 UTC 25, (B) 18 UTC 25, (C) 00 UTC 26, (D) 06 UTC 26, (E) 12 UTC 26, and (F) 18 UTC March 26, 2014. The large solid dot denotes the SEC center.

over the east and northwest of the SEC enhanced evidently and indicated a pronounced mesoscale structure over the east and northwest. The precipitation was contributed from the transportation of water vapor through the strengthend southeastern gale due to the enhancement of the northeastern anticyclone. The northwestern anticyclone intruded to the west of the SEC with a trough of $0^{\circ}$ temperature, bringing in the cold air. The cold intrusion favored the enhancement of the baroclinicity and the precipitation increased the latent heat release. From $6 \mathrm{~h}$ to 12 UTC 26, the northwestern anticyclone continued to intrude with the deepening trough of $0^{\circ}$ temperature. The precipitation 
enhanced over the north and decreased over the east. The deepening rate of the SEC weakened to 2.49 Bergeron. The central SLP decreased to the minimum at 18 UTC 26.

\section{Synoptic-Scale Environment}

The rapid development from 18 UTC 25 to 18 UTC 26, which is $12 \mathrm{~h}$ before and after the moment of the maximum deepening rate at 06 UTC 26, will be examined in this section. Key factors including the baroclinicity, water vapor, vorticity advection and upper-level forcing are investigated at 18 UTC 25 (the moment of early explosive development, $t_{\text {ear }}$ ), 06 UTC 26 (the moment of maximum deepening rate, $t_{\max }$ ), and 18 UTC 26 (the moment of minimum central SLP, $t_{\text {min }}$ ).

At $t_{\text {ear }}$ (Figures 3A1-E1), the deepening rate of central SLP was 1.38 Bergeron (Figure 1B). The distribution of surface turbulent heat fluxes and evaporation was mainly to the southwest and northeast of the SEC (Figure 3A1), providing heat from ocean to atmosphere, and the distribution over the northeast near the precipitation area was stronger than that over the southwest. Meanwhile, the easterlies transported moisture from surrounding areas to the region of precipitation. The SEC was located in a trough of the $850-\mathrm{hPa}$ geopotential height (Figure 3B1). The temperature disturbance had a rather small initial amplitude but lagged the 850 -hPa geopotential height by about $1 / 4$ wavelength, which is ideal for baroclinic development (Sanders, 1971; Warrenfeltz and Elsberry, 1989). The baroclinicity (Eady growth rate) was distributed to the north and northwest of the SEC. The northwestward and southeastward low-level jet streams at $850-\mathrm{hPa}$ appeared to the northwest and east of the SEC, respectively, and of which the northwestward one was stronger (Figure 3C1). The moist tongue of specific humidity around the SEC was more than $5 \mathrm{~g} \mathrm{~kg}^{-1}$. The water vapor convergence was mainly distributed over the northeast of the SEC and was transported by the southeastward low-level jet stream. The SEC strode about 10 longitudes in the downstream of the 500-hPa geopotential height trough with positive vorticity, causing weak cyclonic-vorticity advection around the SEC (Figure 3D1). At $300 \mathrm{hPa}$ (Figure 3E1), the pattern of the geopotential height trough was similar to that at $500 \mathrm{hPa}$ and strode about 10 longitudes upstream of the SEC located in the south of the jet stream. A region of divergence existed about 7 longitudes downstream of the SEC.

At $t_{\max }$ (Figures 3A2-E2), the deepening rate of the central SLP reached its maximum of 3.45 Bergeron (Figure 1B). During the rapid development of the SEC, there was more surface turbulent heat fluxes supply from the ocean along the Gulf Stream to the atmosphere due to the enhancing surface wind speed (Figure 3A2), compared with that at $t_{\text {ear }}$ (Figure 3A1). The precipitation was enhanced in the northwest of the SEC (Figure 2D), due to more evaporation and horizontal moisture convergence (see Figure 6B) by stronger easterlies over this region. At $850 \mathrm{hPa}$ (Figure 3B2), the low vortex deepened to $1,240 \mathrm{~m}$. The temperature field was severely distorted with a warm ridge extending toward to the SEC from the southeast. The baroclinicity enhanced significantly and showed a pattern of the Shapiro-Keyser model. The cold front was located to the southwest, the bent-back front and the warm front were distributed to the northwest and northeast, respectively. Both the northwestward and southeastward lowlevel jet streams strengthened evidently (Figure 3C2), especially the southeastward one enhanced dramatically. Associated with the increasing moist tongue of specific humidity, the stronger southeastward low-level jet stream enhanced water vapor convergence over the northwest and northeast of the SEC, corresponding to the location of the bent-back front and the warm front, where the precipitation occurred (Figure 2D). At $500 \mathrm{hPa}$ (Figure 3D2), the geopotential height trough was amplified significantly with stronger cyclonic vorticity and approached the SEC, causing the enhancement of cyclonicvorticity advection around the SEC. At $300 \mathrm{hPa}$ (Figure 3E2), the approaching trough was amplified and evolved similar to the $500-\mathrm{hPa}$ trough. The SEC moved from the south of the jet stream to the left of the jet stream exit where the strong upper-level forcing happened (Uccellini and Kocin, 1987; Nakamura, 1993), resulting in the divergence around the SEC in the upper troposphere and further enhancement of the ascending motion in the mid-low troposphere.

At $t_{\min }$ (Figures 3A3-E3), the central SLP dropped to the minimum of $953.1 \mathrm{hPa}$ (Figure 1B). The high value area of surface turbulent heat fluxes was enlarged in the south but almost disappeared over the northeast of SEC. The intensity and scale of $850-\mathrm{hPa}$ low vortex continued to strength (Figure 3B3) the baroclinicity was enhanced to the north of the SEC. Meanwhile, the southwestern cold front at $t_{\max }$ weakened. The northwestward low-level jet stream continued to enhance (Figure 3C3), while the southeastward low-level jet stream associated with the specific humidity was moving away from the SEC, resulting in the decrease of the water vapor convergence around the SEC. The height wave was developed into a low vortex and cut off at $500 \mathrm{hPa}$ (Figure 3D3). The cyclonic vorticity and cyclonic-vorticity advection evolved to the downstream of the SEC, resulting in the weakening of the cyclonic-vorticity advection around the SEC. At $300 \mathrm{hPa}$ (Figure 3E3), the trough evolved similarly to the $500-\mathrm{hPa}$ one, except that there was no closed circulation formation. The jet stream moved farther away from the SEC, indicating the decrease of the upper-level forcing and the weakening of the divergence around the SEC.

\section{DIAGNOSTIC RESULTS}

The Z-O equation is used to quantify the contributions from the dynamic and thermodynamic factors, including the vorticity advection, temperature advection, diabatic heating and adiabatic heating. The two-dimensional second-order filtering scheme by Shapiro (1970) cannot filter out all noises due to the nonlinear term and there are some deviation in calculating each term inevitably. However, the comparison between the sum of four terms on the right side (the total tendency in Figure 4, shaded) and the 950-hPa geostrophic vorticity tendency on the left side (LHS, contour in Figure 4) of Equation 2 indicated that their 

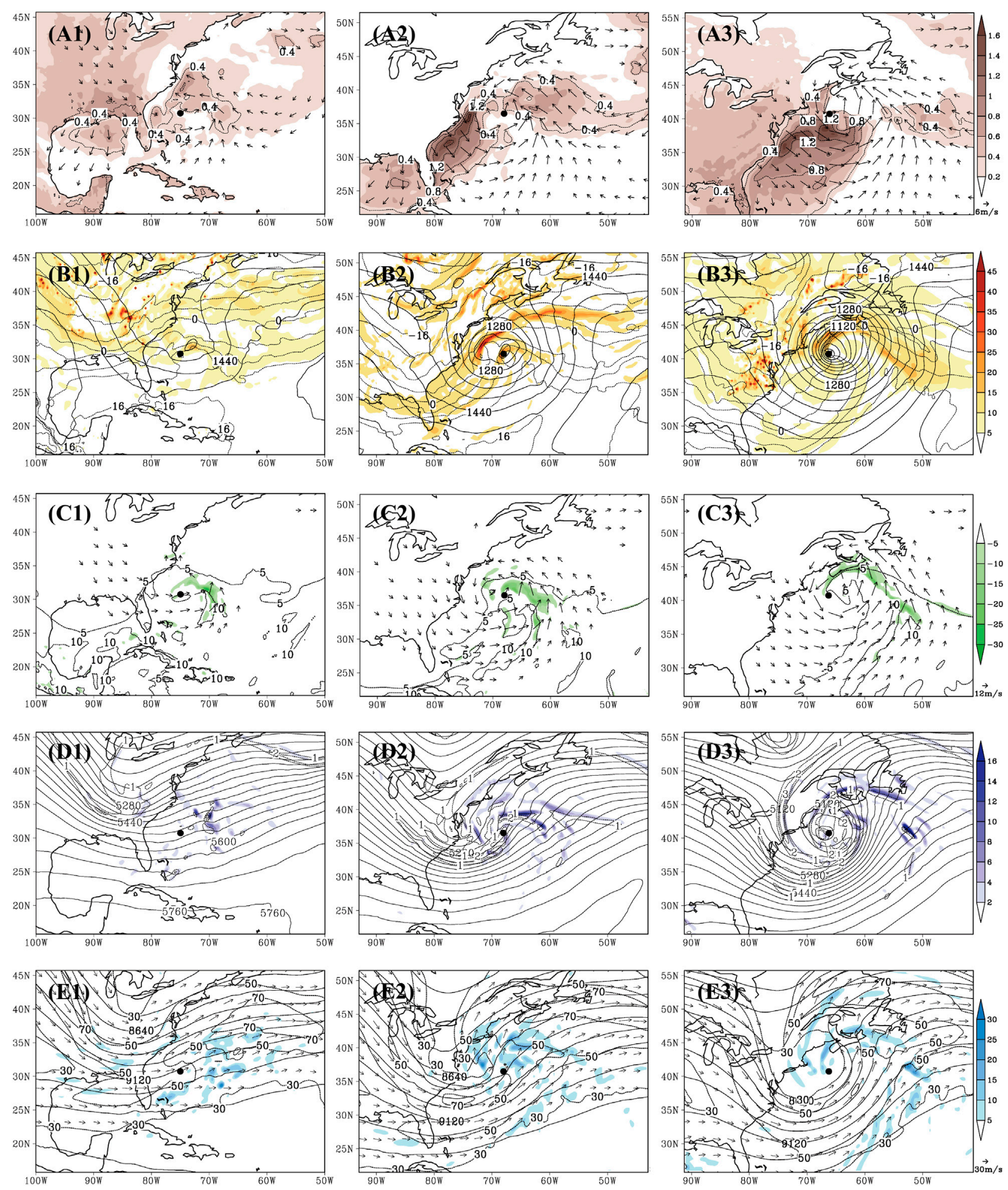

FIGURE 3 | Synoptic weather charts at (A1-E1) 18 UTC 25, (A2-E2) 06 UTC 26, and (A3-E3) 18 UTC March 26, 2014. (A1-A3) Surface heat fluxes (latent and sensible fluxes, shaded, $0.2 \mathrm{~kW} \mathrm{~m}^{-2}$ intervals), evaporation (dashed, $0.4 \mathrm{~mm}$ intervals) and $10 \mathrm{~m}$ wind vector (arrow, $\geq 6 \mathrm{~m} \mathrm{~s}^{-1}$ ); (B1-B3) 850-hPa geopotential height (solid, $40 \mathrm{gpm}$ intervals), temperature (dashed, $4^{\circ} \mathrm{C}$ intervals) and Eady growth rate (shaded, $5 \times 10^{-6} \mathrm{~s}^{-1}$ intervals); (C1-C3) $850-\mathrm{hPa}$ jet stream (arrow, $\geq 12 \mathrm{~m} \mathrm{~s}{ }^{-1}$ ), specific humidity (dashed, $5 \mathrm{~g} \mathrm{~kg}^{-1}$ intervals) and water vapor convergence (shaded, $5 \times 10^{-4} \mathrm{~g} \mathrm{~kg}^{-1} \mathrm{~s}^{-1}$ intervals); (D1-D3) $500-\mathrm{hPa}$ geopotential height (solid, $40 \mathrm{gpm}$ intervals), vorticity (dashed, $1 \times 10^{-4} \mathrm{~s}^{-1}$ intervals) and vorticity advection (shaded, $2 \times 10^{-9} \mathrm{~s}^{-2}$ intervals); (E1-E3) 300-hPa geopotential height (solid, $120 \mathrm{gpm}$ intervals), wind vector (arrow, $\geq 30 \mathrm{~m} \mathrm{~s}^{-1}$ ), jet stream (dashed, $\geq 30 \mathrm{~m} \mathrm{~s}^{-1}$ ) and divergence (shaded, $3 \times 10^{-5} \mathrm{~s}^{-1}$ intervals). The large solid dot denotes the SEC center. 

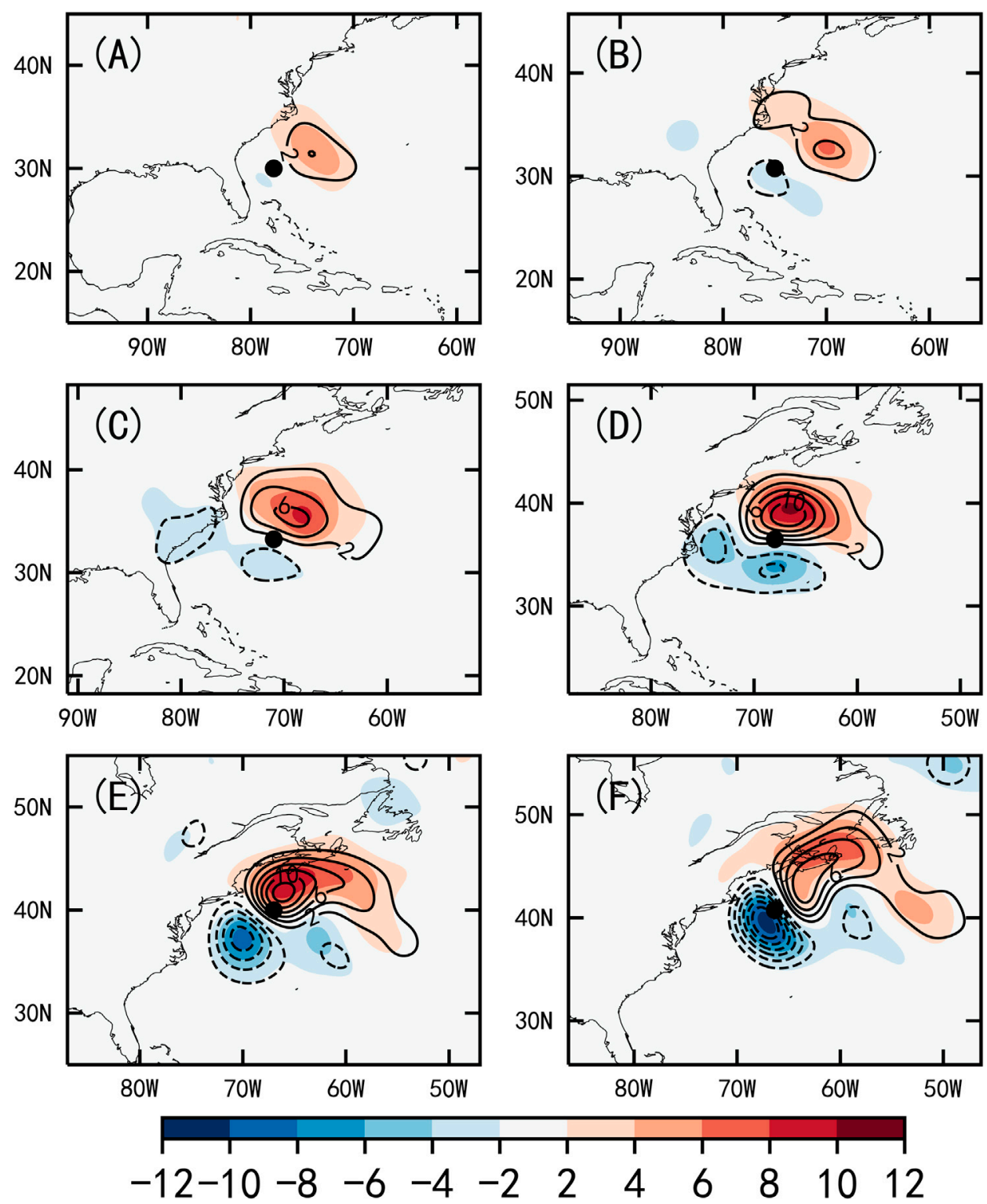

FIGURE 4 | The 950-hPa geostrophic vorticity tendency (the term on the left side of Eq. 2 (LHS), contour interval is $2 \times 10^{-9} \mathrm{~s}^{-2}$ ) and the total tendency (shaded, the sum of four terms on the right side of Equation 2, the interval is $2 \times 10^{-9} \mathrm{~s}^{-2}$ ) of the SEC at (A) 12 UTC 25, (B) 18 UTC 25, (C) 00 UTC 26 , (D) 06 UTC 26, (E) 12 UTC 26, and (F) 18 UTC March 26, 2014. The large solid dot denotes the SEC center.

pattern and magnitude were quite similar in general, suggesting the reasonableness of the result.

At 12 UTC 25 (Figure 4A, shaded), the total tendency of $4 \times 10^{-9} \mathrm{~s}^{-2}$ from the $\mathrm{Z}-\mathrm{O}$ equation was centered on the northeast of the SEC. From 12 UTC 25 to 00 UTC 26 (Figures 4A-C, shaded), it was gradually enhanced to $8 \times 10^{-9} \mathrm{~s}^{-2}$ and the deepening rate of the SEC was also increased (Figure 1B). At 06 UTC 26 (Figure 4D, shaded), its intensity was enhanced to the maximum of $10 \times 10^{-9} \mathrm{~s}^{-2}$ and the deepening rate of the SEC reached the maximum of 3.45 Bergeron at the same time (Figure 1B). At 12 UTC 26 (Figure 4E), the intensity of the total tendency began to weaken to $8 \times 10^{-9} \mathrm{~s}^{-2}$ and the deepening rate of the SEC also began to decrease. The total tendency and the deepening rate continued to weaken till 18 UTC 26 (Figure 4F, shaded). The results indicated that the total tendency of the Z-O equation had similar evolution with the deepening rate of the SEC, showing the reasonableness of the result calculated by the $\mathrm{Z}-\mathrm{O}$ equation.

Moreover, it is found that the positive total tendency moved closer to the SEC center during the increase of the deepening rate from 12 UTC 25 to 00 UTC 26 and moved away from the SEC center during the decrease of the deepening rate from 06 UTC 26 to 18 UTC 26. 


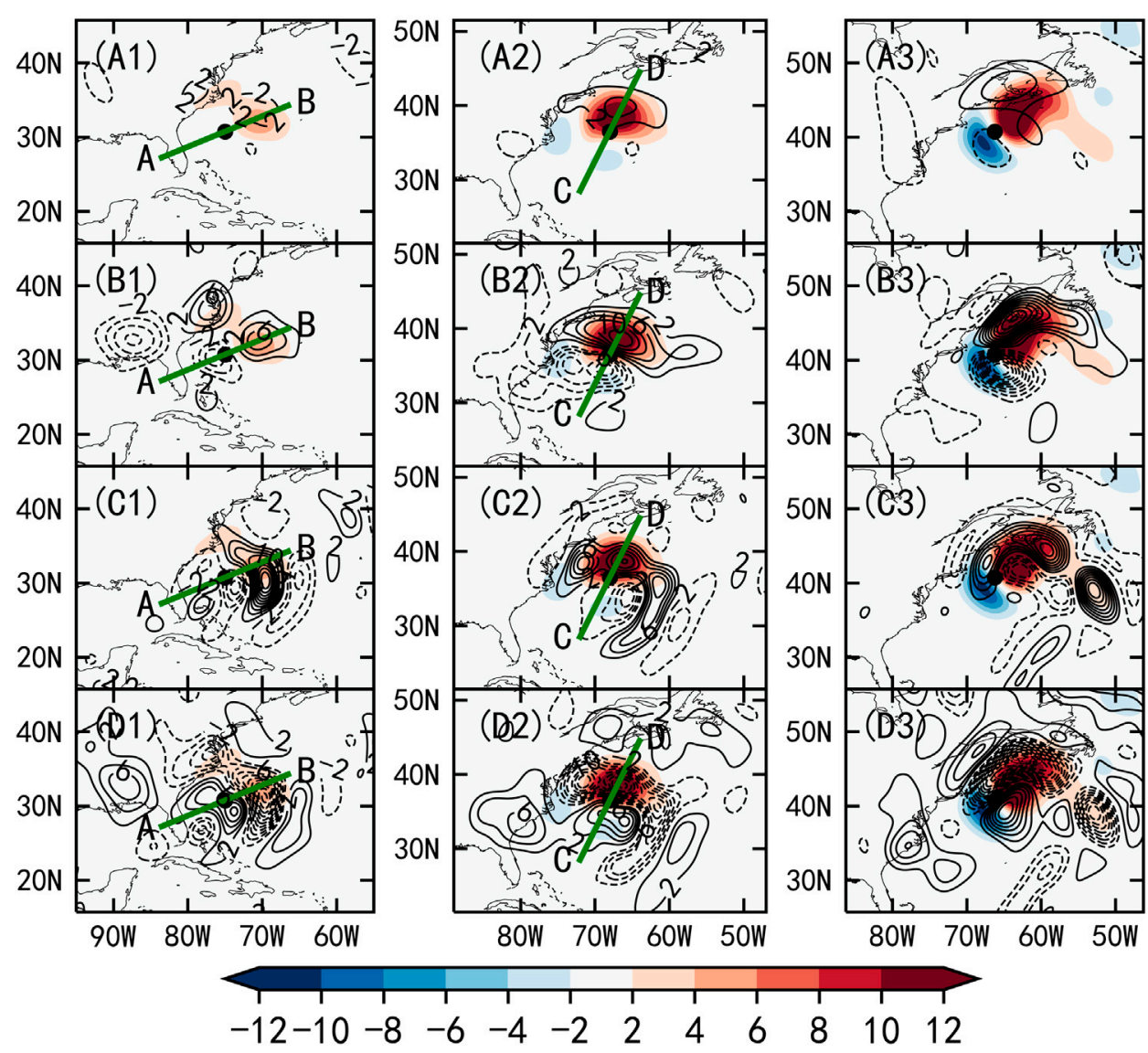

FIGURE 5 | Contributions of individual terms (contours, $2 \times 10^{-9} \mathrm{~s}^{-2}$ intervals) to the total tendency (shaded, $2 \times 10^{-9} \mathrm{~s}^{-2}$ intervals) at (A1-D1) 18 UTC 25 , (A2-D2) 06 UTC 26, and (A3-D3) 18 UTC March 26, 2014. The large solid dot denotes the SEC center. (A1-A3) the cyclonic-vorticity advection, (B1-B3) the warm-air advection, (C1-C3) the diabatic heating, (D1-D3) the adiabatic heating. The lines of A-B and C-D are the cross sections in Panel 7

\section{Vertically Integrated Characteristics}

In order to focus on the SEC evolution, the diagnostic domain is moving with the SEC and extending over 30 latitudes and 40 longitudes regarding to the SEC center. At $t_{\text {ear }}$ (Figures 5A1-D1), the integrated cyclonic-vorticity advection center (term $\mathrm{A}$ in Equation 2) of $2 \times 10^{-9} \mathrm{~s}^{-2}$ was located to the northeast of the SEC (Figure 5A1). The integrated warm-air advection center (term B in Equation 2) of $6 \times 10^{-9} \mathrm{~s}^{-2}$ was distributed to the northeast of the SEC and the integrated cold-air advection center of $-6 \times 10^{-9} \mathrm{~s}^{-2}$ was around the SEC center (Figure 5B1). The integrated diabatic heating (term $\mathrm{C}$ in Equation 2) with the center value of $18 \times 10^{-9} \mathrm{~s}^{-2}$ was distributed to the southwest of the SEC (Figure 5C1). The pattern of the integrated adiabatic cooling due to the ascending motion (term D in Equation 2) was generally opposite to the integrated diabatic heating and was located to the southwest of the SEC, with the center value of $-18 \times$ $10^{-9} \mathrm{~s}^{-2}$ (Figure 5D1). A $10^{\circ} \times 10^{\circ}$ area with the SEC as the center was selected to calculate the mean contributions of each term to the total tendency, and the results were shown in Figure 6A. It can be seen that the diabatic heating was the largest $(1.06 \times$ $\left.10^{-9} \mathrm{~s}^{-2}\right)$ and much greater than the cyclonic-vorticity advection $\left(0.58 \times 10^{-9} \mathrm{~s}^{-2}\right)$ and warm-air advection $\left(0.13 \times 10^{-9} \mathrm{~s}^{-2}\right)$ at $\mathrm{t}_{\mathrm{ear}}$, indicating that the early explosive development was initiated primarily by the diabatic heating.

At $t_{\max }$ (Figures 5A2-D2), the integrated cyclonic-vorticity advection was located closely to the north of the SEC, the intensity was enhanced to $4 \times 10^{-9} \mathrm{~s}^{-2}$ and the scale was enlarged (Figure 5A2). The integrated warm-air advection increased to $12 \times 10^{-9} \mathrm{~s}^{-2}$ over the northwest of the SEC (Figure 5B2) and moved closer to the SEC center. The integrated diabatic heating rotated cyclonically around the SEC center (Figure 5C2) and showed a pronounced mesoscale structure with three centers, corresponding to the warm front over the east and the bent-back front over the north and northwest, respectively. The intensity was weakened slightly to $12 \times 10^{-9} \mathrm{~s}^{-2}$. The pattern of the integrated adiabatic cooling was almost opposite to the integrated diabatic heating and the intensity increased to $-20 \times 10^{-9} \mathrm{~s}^{-2}$ (Figure 5D2). From $t_{\text {ear }}$ to $t_{\max }$, both the integrated cyclonic-vorticity advection and the integrated warm-air advection evolved cyclonically and closed to the northeast of the SEC and their intensity increased distinctively. The integrated diabatic heating was close to the SEC center, although it weakened slightly. These resulted in the significant growth of the area mean integrated diabatic heating, integrated warm-air advection and integrated 

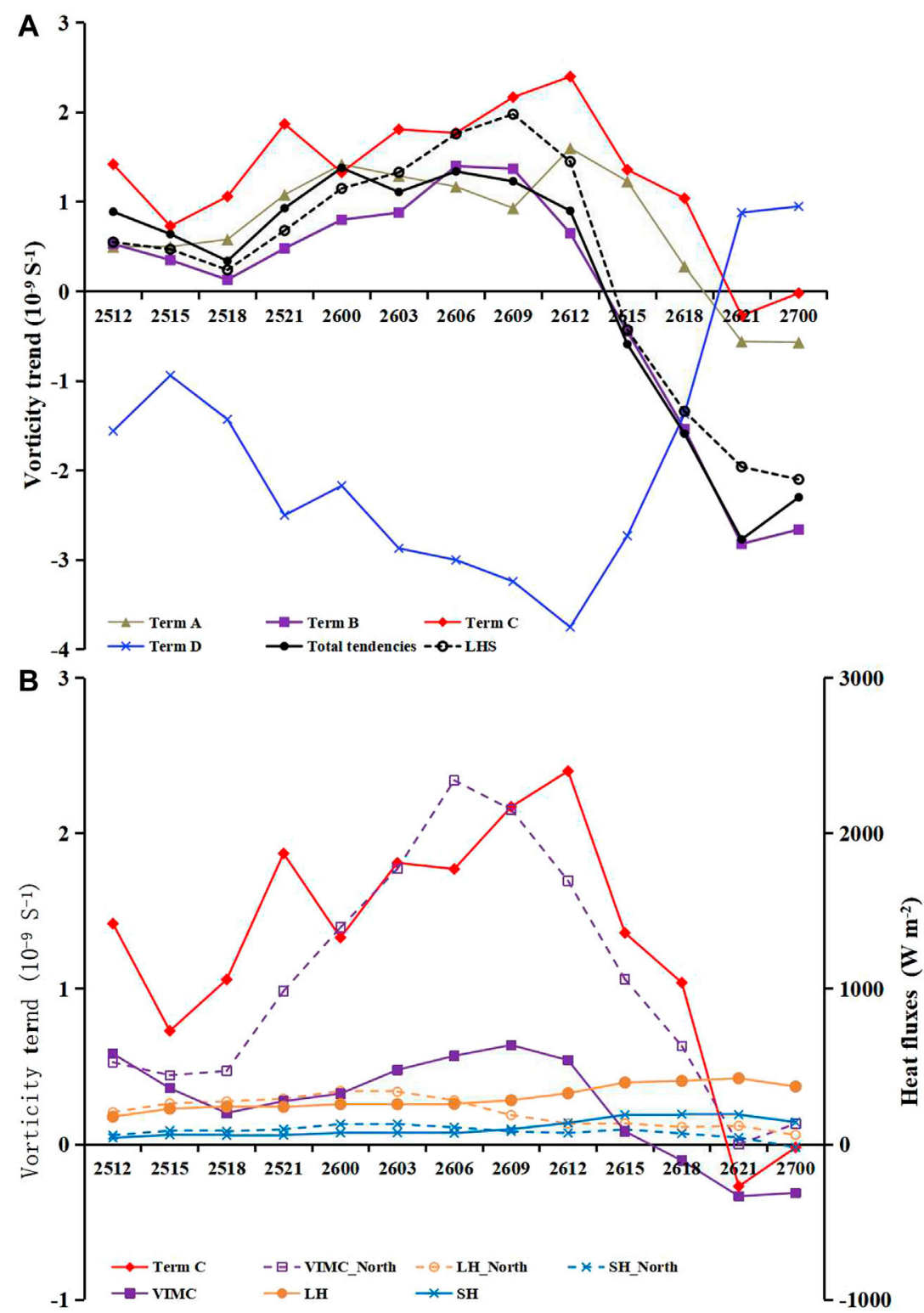

FIGURE 6 | (A) Evolution of the area mean cyclonic-vorticity advection (Term A, brown), warm-air advection (Term B, purple), diabatic heating (Term C, red), adiabatic heating (Term D, blue), total tendencies (black) and the 950-hPa geostrophic vorticity tendency (dashed, LHS of Eq. 2). The area is $10^{\circ} \times 10^{\circ}$ and moved with the SEC as the center. (B) Evolution of the area mean diabatic heating (Term C, red), surface sensible heat fluxes (SH, blue), surface latent heat fluxes ( $\mathrm{LH}$, orange) and vertically integrated moisture convergence (VIMC, converted to unit of $\mathrm{W} \mathrm{m}^{-2}$, purple). The “_North" indicates the north half area mean $\left(10^{\circ}\right.$ longitudes $\times 5^{\circ}$ latitudes) over the north of SEC center.

cyclonic-vorticity advection (Figure 6A). The warm-air advection had the biggest growth (increased $1.27 \times 10^{-9} \mathrm{~s}^{-2}$ within $12 \mathrm{~h}$ ), followed by the diabatic heating (increased $0.71 \times 10^{-9} \mathrm{~s}^{-2}$ within $12 \mathrm{~h}$ ) and the cyclonic-vorticity advection (increased $0.59 \times 10^{-9} \mathrm{~s}^{-2}$ within $12 \mathrm{~h}$ ). The contribution of the diabatic heating was still the largest $\left(1.77 \times 10^{-9} \mathrm{~s}^{-2}\right)$, followed by the warm-air advection $(1.40 \times$ $\left.10^{-9} \mathrm{~s}^{-2}\right)$ and the cyclonic-vorticity advection $\left(1.17 \times 10^{-9} \mathrm{~s}^{-2}\right)$ (Figure 6A).

At $t_{\min }$ (Figures 5A3-D3), the integrated cyclonic-vorticity advection over the northeast moved away from the SEC and the integrated anticyclonic-vorticity advection over the southwest moved closer to the SEC (Figure 5A3). Although the integrated warm-air advection was strengthened over the northeast (Figure 5B3), the SEC became detached from the warm-air advection region and located in the area of the coldair advection. The integrated diabatic heating was distributed to the west and northeast of the SEC (Figure 5C3). The western center was close to the SEC, the northeastern center was enhanced but moved away from the SEC. The adiabatic cooling increased but kept away from the SEC 
(Figure 5D3). From $t_{\max }$ to $t_{\min }$, the integrated cyclonicvorticity advection, warm-air advection, and diabatic heating generally moved away from the SEC, even though their intensity unchanged or enhanced, resulting in significant weakening of the area mean of each term around the SEC center (Figure 6A).

According to the above analysis associated with the synoptic study in section 3, corresponding to the water vapor convergence (Figure 3C1) and precipitation (Figure 2B) to the east of the SEC at $t_{\text {ear }}$, the diabatic heating resulted from the latent heat release contributed the biggest to the early explosive development (Figure 5C1). Due to the relatively longer distance about 10 longitudes between the SEC and the mid-upper trough in the upstream (Figures 3D1,E1), the contribution of the cyclonicvorticity advection was weaker than the diabatic heating (Figure 6A). Consistent with the small amplitude of temperature disturbance (Figure 3B1), the contribution of the warm-air advection was the smallest (Figure 6A). During the rapid development from $t_{\text {ear }}$ to $t_{\max }$, the diabatic heating evolved closely to the SEC center (Figure 5C2), causing the increasing contribution of the diabatic heating (Figure 6A). Moreover, it turned out that the distribution of the diabatic heating has a pronounced mesoscale structure and has two main separated areas: the north part (in the vicinity of the bent-back front) and the east part (in the vicinity of the warm front). The SEC was centered in the low-level warm ridge with increased amplitude (Figure 3B2). The warm-air advection was enhanced and approached the SEC (Figure 5B2), resulting in the enhancement of the warm-air advection (Figure 6A). The mid-upper level geopotential height trough with cyclonic vorticity approached the SEC (Figures 3D2,E2), and the cyclonic-vorticity advection was enhanced around the SEC (Figure 5A2). Figure 6A showed the evolutions of the area mean total and individual terms from 12 UTC 25 to 00 UTC 27 . The good variability agreement between the sum of four terms (total tendency) and the 950-hPa geostrophic vorticity tendency (LHS) indicates once again the reasonableness of the results calculated from the $\mathrm{Z}-\mathrm{O}$ equation. During the rapid development of the SEC from 18 UTC 25 to 18 UTC 26, the contribution of the diabatic heating was generally larger than the cyclonic-vorticity advection and warm-air advection, suggesting that the diabatic heating played more important role during the rapid development of the SEC over the Gulf Stream.

Additionally, the evolution of the area mean surface sensible and latent heat fluxes and vertically integrated moisture convergence (VIMC) has been examined. The hourly VIMC has been converted to the energy flux (unit of $\mathrm{W} \mathrm{m}^{-2}$ ) by multiplying the latent heat of vaporization of water $\left(2.5 \times 10^{6} \mathrm{~J} / \mathrm{kg}\right)$ and considering the time interval of $1 \mathrm{~h}(3,600 \mathrm{~s})$, for the unit consistence with the sensible and latent heat fluxes. The results were shown in Figure 6B. The area mean VIMC showed similar variability with the diabatic heating, while the surface sensible and latent heat fluxes were monotonically increasing. As the surface turbulent heat fluxes associated with abundant moisture was transported from ocean to atmosphere over the precipitation region by stronger easterlies over the north of the SEC (Figures 3A1,A2), so the north half of the mean area $\left(10^{\circ}\right.$ longitudes $\times 5^{\circ}$ latitudes) over the north of the SEC was selected to examine the effect of surface sensible and latent heat fluxes on the explosive development. The north area mean of sensible and latent heat fluxes (SH_North and LH_North) and VIMC (VIMC_North) were generally enhanced from 12 UTC 25 to 06 UTC 26 and then weakened, similar to the variability of the deepening rate (Figure 1B) and the diabatic heating (Figure 6B, red), moreover, the area mean over the north was usually larger than that over the whole area, indicating that the processes over the north of the SEC center had more significant influences on the rapid development, consistent with the results of Figures 3A1-A3. The diabatic heating was mainly from the condensation of moisture transported from horizontal (i.e., vertically integrated moisture convergence) and vertical (i.e., surface latent heat flux) directions. Although, the variability of the surface latent heat flux and vertically integrated moisture convergence was similar, the increasing rate of surface latent heat flux was much smaller than that of the vertically integrated moisture convergence during the rapid development. The surface latent heat flux had some contributions to the initial development of the SEC, but the contribution became negligible at the later stage.

\section{Cross Section}

The cross sections described in Methods are further discussed at $t_{\text {ear }}$ and $t_{\max }$ to explore the physical process contributions to the rapid SEC development. The cross section passes through the SEC center and the total tendency center (green line in Figures 5A1-D1). The cross sections of the cyclonic-vorticity advection, warm-air advection, diabatic heating and adiabatic heating at $t_{\text {ear }}$ are shown in Figures 7A1-D1. The cyclonic-vorticity advection greater than $0.2 \times 10^{-9} \mathrm{~s}^{-2}$ appeared between the $700-300 \mathrm{hPa}$ in the downstream of the SEC (Figure 7A1), its intensity was relatively weak, corresponding to the weak geopotential height trough at $500 \mathrm{hPa}$ and $300 \mathrm{hPa}$ (Figures 3D1,E1). The warm-air advection was mainly distributed below $400 \mathrm{hPa}$ with a maximum near $700 \mathrm{hPa}\left(0.8 \times 10^{-9} \mathrm{~s}^{-2}\right)$ in the downstream of the SEC. Moreover, a weak center of $0.4 \times 10^{-9} \mathrm{~s}^{-2}$ was located near $250 \mathrm{hPa}$ above the SEC (Figure 7B1). The cold-air advection was below $400 \mathrm{hPa}$ and above the SEC, which offset the warm-air advection, causing the weak area mean warm-air advection (Figure 6A). The diabatic heating resulted from the latent heat release dominated between the $900-300 \mathrm{hPa}$ with the center of $1.0 \times 10^{-9} \mathrm{~s}^{-2}$ at $600 \mathrm{hPa}$ (Figure 7C1) in the downstream of the SEC, where the warm front was located (Figure 3B1), the water vapor converged (Figure 3C1) and the precipitation (Figure 2B) occurred. The adiabatic cooling due to the ascending motion was concentrated between the $900-300 \mathrm{hPa}$ with a center value of $-1.4 \times 10^{-9} \mathrm{~s}^{-2}$ near $600 \mathrm{hPa}$ in the downstream of the SEC (Figure 7D1).

Figures 7A2-D2 showed cross sections of each term at $t_{\max }$ (green line in Figures 5A2-D2). The center value of the cyclonic-vorticity advection was doubled to $0.4 \times 10^{-9} \mathrm{~s}^{-2}$ at $300 \mathrm{hPa}$ (Figure 7A2) and its area was enlarged, due to the strengthened trough and cyclonic vorticity advection in the mid-upper troposphere (Figures 3D2,E2). The warm-air advection had two centers, one in the mid-low troposphere near $600 \mathrm{hPa}$ was enhanced and moved closer to the SEC center, the other one in the upper troposphere was enhanced significantly (Figure 7B2). The warm-air 


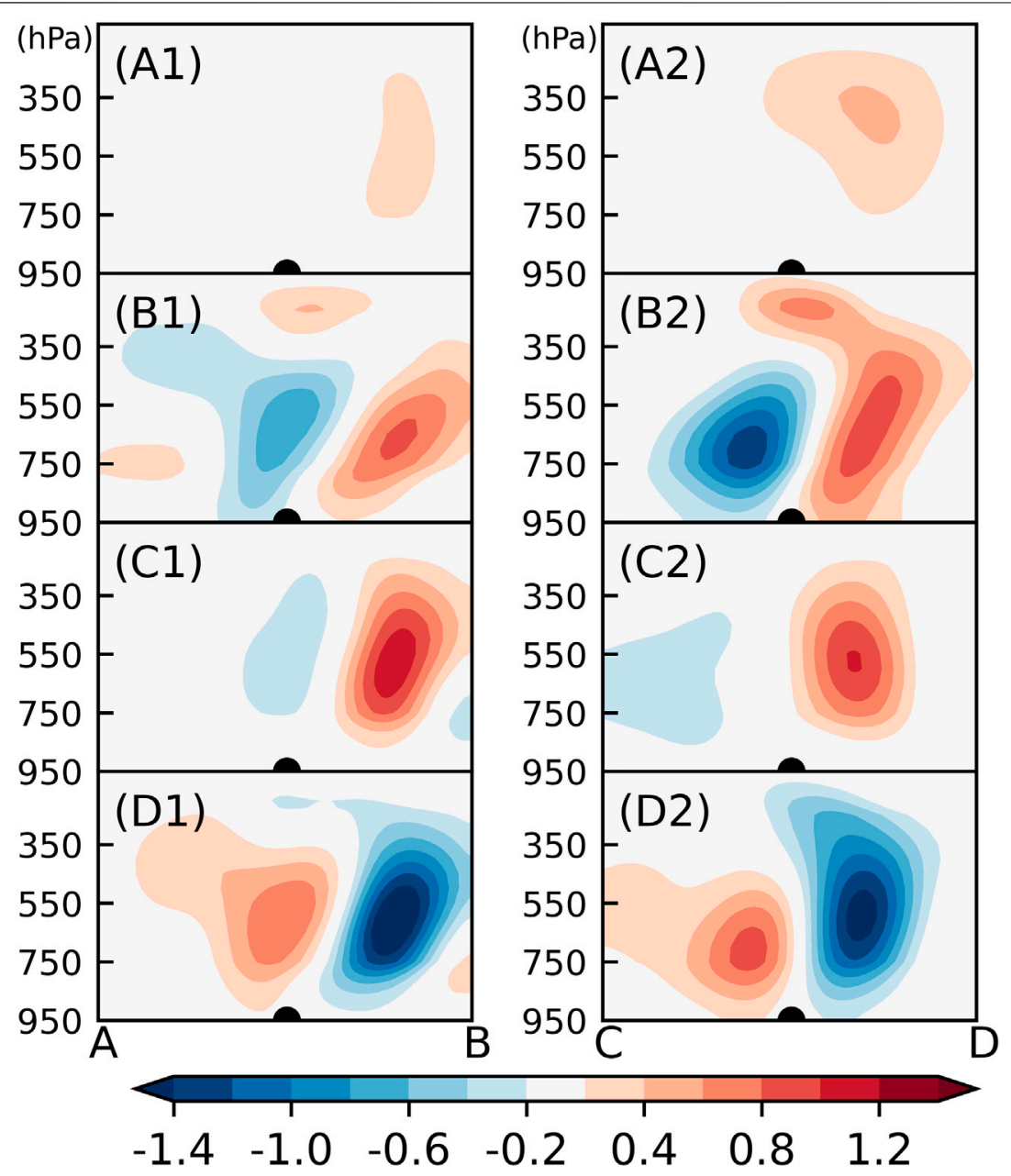

FIGURE 7 | Vertical cross sections of the cyclonic-vorticity advection [(A1, A2), $0.2 \times 10^{-9} \mathrm{~s}^{-2}$ intervals], warm-air advection [(B1, B2), $0.2 \times 10^{-9} \mathrm{~s}^{-2}$ intervals], diabatic heating $\left[(\mathbf{C} 1, \mathbf{C} 2), 0.2 \times 10^{-9} \mathrm{~s}^{-2}\right.$ intervals] and adiabatic heating [(D1, D2), $0.2 \times 10^{-9} \mathrm{~s}^{-2}$ intervals] along the lines A-B and C-D as illustrated in Panel $\mathbf{5}$ (green lines). The lines are selected to pass through the SEC center and the total tendency center. $\mathbf{A : ~}\left(27.25^{\circ} \mathrm{N}, 83.5^{\circ} \mathrm{W}\right), \mathbf{B}:\left(34.25^{\circ} \mathrm{N}, 66.5^{\circ} \mathrm{W}\right), \mathbf{C :}\left(29.5^{\circ} \mathrm{N}, 71.5^{\circ} \mathrm{W}\right), \mathbf{D}:\left(43.5^{\circ} \mathrm{N}\right.$, 64.5'W). (A1-D1) 18 UTC 25, (A2-D2) 06 UTC March 26, 2014. The large solid dot denotes the SEC center.

advection in the upper troposphere was in agreement with Hirschberg and Fritsch (1991), who showed that the warm-air advection in the upper troposphere, superimposed up the lower-level baroclinicity or in combination with other forcing factors, could enhance the cyclone development. The diabatic heating was concentrated between the 900-300 hPa and centered near $600 \mathrm{hPa}$ with the center value of $1.0 \times 10^{-9} \mathrm{~s}^{-2}$ (Figure 7C2). Its intensity maintained, but the location also became closer to the SEC center, strengthening the contribution of the diabatic heating (Figure 6A). The adiabatic cooling area was enlarged and its intensity was basically unchanged.

\section{DISCUSSION AND CONCLUSION}

The physical process contributions to the development of a SEC migrating over the Gulf Stream from 25 to March 29, 2014 was studied using ERA5 data from ECMWF. This SEC was the most explosive one in the last 20 years, with the maximum deepening rate of 3.45 Bergeron (Figure 1B). During its rapid development (Figure 2), the northwestern anticyclone associated with the cold air intrusion to the west of the SEC caused the northwestern gale, suggesting that the baroclinicity favored the rapid development. The northeastern anticyclone and gale were strengthened, favoring the precipitation over the east and northwest of the SEC. The precipitation was significantly enhanced during the rapid development.

At the maximum-deepening-rate moment, the precipitation showed a pronounced mesoscale structure, which has centers to the north and northeast of the SEC (Figure 2D). The SEC migrated along the southeastern periphery of the Gulf Stream during its development stage (Figure 1A). The easterlies to the northern side of the SEC, known as cold conveyor belt with cold and dry air (Carlson, 1980; Schultz, 2001; Schemm and Wernli, 2014), facilitated more moisture flux from the Gulf Stream and 
transported to the bent-back front. These surface processes favored the precipitation and further enhanced the latent heat release over the bent-back front. The evolution of the $850 \mathrm{hPa}$ temperature resembled (Figures 3B1-B3) the Shapiro-Keyser model (Neiman and Shapiro, 1993) with the frontal T-bone structure. The bent-back front and the warm front were dominated by the water vapor convergence in the mid-low troposphere, the cyclonic-vorticity advection in the mid-upper troposphere and the divergence in the upper troposphere (Figures 3C2-E2). The mesoscale structure of precipitation (Figure 2) corresponds to the bent-back front and the warm front, resulted from the water vapor convergence associated with the mid-low level front, mid-upper level cyclonic-vorticity advection and the upper level divergence. These key factors of the baroclinicity, water vapor convergence, cyclonic-vorticity advection and divergence were generally enhanced during the rapid development of the SEC and their combination from the low to upper troposphere forced the rapid development of the SEC.

The Z-O equation was used to diagnose the contributions of the thermodynamic and dynamic factors quantitatively. The results suggested that the early explosive development of the SEC was mainly forced by the diabatic heating resulted from the latent heat release at $t_{\text {ear. }}$. The combination of the diabatic heating, warm-air advection and cyclonic-vorticity advection forced the most explosive development at $t_{\max }$, and the diabatic heating had the biggest contribution, followed by the warm-air advection and cyclonic-vorticity advection. During the rapid development from 18 UTC 25 to 18 UTC 26, the diabatic heating always had the biggest contribution (Figure 6A), indicating that the diabatic heating played the most important role in the whole process of rapid development, which is different from the previous results. For example, Lupo et al. (1992) revealed that the contribution of the diabatic heating was generally smaller than those of the cyclonic-vorticity advection and warm-air advection for the EC off the coast of New England, some results showed strong baroclinicity of ECs over the Northwestern Atlantic (Bosart, 1981; Gyakum, 1983a, 1983b; Anthes et al., 1983; Sanders, 1986; Manobianco, 1989; Wang and Rogers, 2001). The surface heat and moisture fluxes from the Gulf Stream turned to be much stronger than those over the Northwestern Atlantic (Kuo et al., 1991b), resulting in the larger contribution of the diabatic heating. Although the diabatic heating was the most important factor during the rapid development of the SEC, its relative contribution varied at different stages. From the early explosive-developing moment to the maximum-deepening-rate moment, the relative contribution of the diabatic heating weakened, while the relative contributions of the cyclonicvorticity advection and warm-air advection enhanced, differing from the previous studies of Gyakum (1983a, 1983b), Anthes et al. (1983) and Strahl and Smith (2001), who suggested that the latent heat release played an major role in the later stages of the EC development. In the current study, the surface latent heat flux had some contributions to the initial development of the SEC, but the contribution became negligible at the later stage (Figure 6B).

The cross section constructed using an updated method suggested that during the rapid development, the cyclonicvorticity advection was distributed and enhanced in the mid- upper troposphere, in agreement with the marine explosive cyclone studied by Lupo et al. (1992). The warm-air advection had two centers in the mid-low (near $600 \mathrm{hPa}$ ) and upper (near $200 \mathrm{hPa}$ ) troposphere, and the center in mid-low troposphere was stronger than the center in upper troposphere, differing from the weaker center in mid-low troposphere and stronger center in upper troposphere in Lupo et al. (1992). The diabatic heating stretched to $300 \mathrm{hPa}$, which is higher than $500 \mathrm{hPa}$ in Lupo et al. (1992). Probably, the heat and moisture fluxes from the Gulf Stream in the Western Atlantic is larger than these from the Northwestern Atlantic (Kuo et al., 1991b), which strengthens the warm-air advection in the mid-low troposphere and latent heat release in middle troposphere. Further study is needed in order to understand different contributions of each physical process during different developed stages between ECs with different intensity. Additionally, the surface heat and moisture fluxes from the Gulf Stream can enhance the precipitation and latent heat release over the bent-back front and favor the rapid development, while the Z-O equation can't explain the processes directly, more numerical experiments of the contribution of the surface sensible and latent heat fluxes to the EC development are needed in further studies.

\section{DATA AVAILABILITY STATEMENT}

The original contributions presented in the study are included in the article/Supplementary Material, further inquiries can be directed to the corresponding authors.

\section{AUTHOR CONTRIBUTIONS}

Conceptualization, SZ, YX and CL; method, SZ, CL, HM and JX; software, SJZ and $\mathrm{ZH}$; data curation, SZ and YZ; writing-original draft preparation, $S Z$ and $Z G$; writing-review and editing, SZ, CL, HM and RT; visualization, SJZ, $\mathrm{ZH}$ and YZ; All authors have read and agreed to the published version of the manuscript.

\section{FUNDING}

This research was supported by the National Key Research and Development Project (2018YFC1506902), Project of Enhancing School with Innovation of Guangdong Ocean University (230419106), Guangdong Ocean University $\mathrm{PhD}$. Scientific Research Program (R19045) and the National Natural Science Foundation of China (42075036).

\section{ACKNOWLEDGMENTS}

The authors express their sincere thanks to Gang $\mathrm{Fu}$ and Pengyuan Li from Ocean University of China for their comments on this article. Special thanks are given to ECMWF for providing ERA5 data. We would like to thank the reviewers for their valuable suggestions and comments. 


\section{REFERENCES}

Allen, J. T., Pezza, A. B., and Black, M. T. (2010). Explosive Cyclogenesis: A Global Climatology Comparing Multiple Reanalyses. J. Clim. 23, 6468-6484. doi:10.1175/2010jcli3437.1

Anthes, R. A., Kuo, Y.-H., and Gyakum, J. R. (1983). Numerical Simulations of a Case of Explosive marine Cyclogenesis. Mon. Wea. Rev. 111, 1174-1188. doi:10.1175/1520-0493(1983)111<1174: nsoaco $>2.0 . \operatorname{co} ; 2$

Azad, R., and Sorteberg, A. (2014). The Vorticity Budgets of North Atlantic Winter Extratropical Cyclone Life Cycles in MERRA Reanalysis. Part I: Development Phase*. J. Atmos. Sci. 71, 3109-3128. doi:10.1175/jas-d-130267.1

Blier, W., and Wakimoto, R. M. (1995). Observations of the Early Evolution of an Explosive Oceanic Cyclone during ERICA IOP 5. Part I: Synoptic Overview and Mesoscale Frontal Structure. Mon. Wea. Rev. 123, 1288-1310. doi:10.1175/ 1520-0493(1995)123<1288:ooteeo >2.0.co;2

Booth, J. F., Thompson, L., Patoux, J., and Kelly, K. A. (2012). Sensitivity of Midlatitude Storm Intensification to Perturbations in the Sea Surface Temperature Near the Gulf Stream. Mon. Wea. Rev. 140, 1241-1256. doi:10.1175/mwr-d-11-00195.1

Bosart, L. F., and Lin, S. C. (1984). A Diagnostic Analysis of the President's Day Storm of February 1979. Mon. Wea. Rev. 112, 2148-2177. doi:10.1175/15200493(1984)112<2148:adaotp >2.0.co;2

Bosart, L. F. (1981). The President's Day Snowstorm of 18-19 February 1979: A Subsynoptic-Scale Event. Mon. Wea. Rev. 109, 1542-1566. doi:10.1175/15200493(1981)109<1542:tpdsof $>2.0$. co;2

Carlson, T. N. (1980). Airflow through Midlatitude Cyclones and the Comma Cloud Pattern. Mon. Wea. Rev. 108, 1498-1509. doi:10.1175/1520-0493(1980) $108<1498$ :atmcat $>2.0$. co; 2

Chang, S. W., Alliss, R. J., Raman, S., and Shi, J.-J. (1993). SSM/I Observations of ERICA IOP 4 marine Cyclone: A Comparison with In Situ Observations and Model Simulation. Mon. Wea. Rev. 121, 2452-2464. doi:10.1175/15200493(1993) 121<2452:sooeim >2.0.co;2

Chang, S. W., Holt, T. R., and Sashegyi, K. D. (1996). A Numerical Study of the ERICA IOP 4 marine Cyclone. Mon. Wea. Rev. 124, 27-46. doi:10.1175/15200493(1996) $124<0027$ :ansote $>2.0 . c 0 ; 2$

Davis, C. A., and Emanuel, K. A. (1991). Potential Vorticity Diagnostics of Cyclogenesis. Mon. Wea. Rev. 119, 1929-1953. doi:10.1175/1520-0493(1991) 119<1929:pvdoc >2.0.co;2

Eady, E. T. (1949). Long Waves and Cyclone Waves. Tellus 1, 133-152. doi:10.3402/tellusa.v1i3.8507

Fu, G., Sun, Y., Sun, J., and Li, P. (2020). A 38-year Climatology of Explosive Cyclones over the Northern Hemisphere. Adv. Atmos. Sci. 37 (2), 143-159. doi:10.1007/s00376-019-9106-x

Gyakum, J. R., Anderson, J. R., Grumm, R. H., and Gruner, E. L. (1989). North Pacific Cold-Season Surface Cyclone Activity: 1975-1983. Mon. Wea. Rev. 117, 1141-1155. doi:10.1175/1520-0493(1989)117<1141:npcssc >2.0.co;2

Gyakum, J. R. (1991). Meteorological Precursorsto the Explosive Intensifification of the QE II Storm. Mon. Wea. Rev. 119, 1156-1173. doi:10.1175/15200493(1991)119<1105:mpttei $>2.0$. co;2

Gyakum, J. R. (1983a). On the Evolution of theQE IIStorm. I: Synoptic Aspects. Mon. Wea. Rev. 111, 1137-1155. doi:10.1175/1520-0493(1983)111<1137: oteoti>2.0.co; 2

Gyakum, J. R. (1983b). On the Evolution of theQE IIStorm. I: Synoptic Aspects. Mon. Wea. Rev. 111, 1137-1155. doi:10.1175/1520-0493(1983)111<1137: oteoti>2.0.co;2

Hersbach, H., Bell, B., Berrisford, P., Hirahara, S., Horányi, A., Muñoz-Sabater, J., et al. (2020). The ERA5 Global Reanalysis. Q. J. R. Meteorol. Soc. 146, 1999-2049. doi:10.1002/qj.3803

Hirschberg, P. A., and Fritsch, J. M. (1991). Tropopause Undulations and the Development of Extratropical Cyclones. Part I. Overview and Observations from a Cyclone Event. Mon. Wea. Rev. 119, 496-517. doi:10.1175/15200493(1991)119<0496:tuatdo>2.0.co;2

Holton, J. R. (2004). An Introduction to Dynamic Meteorology. 4thed. International Geophysics Series, 88. Academic Press, 535.

Hoskins, B. J., and Valdes, P. J. (1990). On the Existence of Storm-Tracks. J. Atmos. Sci. 47, 1854-1864. doi:10.1175/1520-0469(1990)047<1854:oteost $>2.0 . c 0 ; 2$
Iwao, K., Inatsu, M., and Kimoto, M. (2012). Recent Changes in Explosively Developing Extratropical Cyclones over the Winter Northwestern Pacific. J. Clim. 25, 7282-7296. doi:10.1175/jcli-d-11-00373.1

Kuo, Y.-H., Low-Nam, S., and Reed, R. J. (1991b). Effects of Surface Energy Fluxes during the Early Development and Rapid Intensification Stages of Seven Explosive Cyclones in the Western Atlantic. Mon. Wea. Rev. 119, 457-476. doi:10.1175/1520-0493(1991)119<0457:eosefd >2.0.co;2

Kuo, Y.-H., Reed, R. J., and Liu, Y. (1996). The ERICA IOP 5 Storm. Part III: Mesoscale Cyclogenesis and Precipitation Parameterization. Mon. Wea. Rev. 124, 1409-1434. doi:10.1175/1520-0493(1996)124<1409: teispi $>2.0 . \operatorname{co} ; 2$

Kuo, Y.-H., Shapiro, M. A., and Donall, E. G. (1991a). The Interaction between Baroclinic and Diabatic Processes in a Numerical Simulation of a Rapidly Intensifying Extratropical marine Cyclone. Mon. Wea. Rev. 119, 368-384. doi:10.1175/1520-0493(1991)119<0368:tibbad>2.0.co;2

Liberato, M. L. R., Pinto, J. G., Trigo, I. F., and Trigo, R. M. (2011). Klaus - an Exceptional winter Storm over Northern Iberia and Southern France. Weather 66, 330-334. doi:10.1002/wea.755

Liberato, M. L. R., Pinto, J. G., Trigo, R. M., Ludwig, P., Ordóñez, P., Yuen, D., et al. (2013). Explosive Development of winter Storm Xynthia over the Subtropical North Atlantic Ocean. Nat. Hazards Earth Syst. Sci. 13, 2239-2251. doi:10.5194/ nhess-13-2239-2013

Lim, E.-P., and Simmonds, I. (2002). Explosive Cyclone Development in the Southern Hemisphere and a Comparison with Northern Hemisphere Events. Mon. Wea. Rev. 130, 2188-2209. doi:10.1175/1520-0493(2002)130<2188: ecdits $>2.0$. co;2

Lupo, A. R., Smith, P. J., and Zwack, P. (1992). A Diagnosis of the Explosive Development of Two Extratropical Cyclones. Mon. Wea. Rev. 120, 1490-1523. doi:10.1175/1520-0493(1992)120<1490:adoted >2.0.co;2

Manobianco, J. (1989). Explosive East Coast Cyclogenesis over the West-central North Atlantic Ocean: A Composite Study Derived from ECMWF Operational Analyses. Mon. Wea. Rev. 117, 2365-2383. doi:10.1175/1520-0493(1989) $117<2365$ :eeccot $>2.0 . \operatorname{co} ; 2$

Moore, R. W., Montgomery, M. T., and Davies, H. C. (2008). The Integral Role of a Diabatic Rossby Vortex in a Heavy Snowfall Event. Mon. Wea. Rev. 136, 1878-1897. doi:10.1175/2007mwr2257.1

Morris, W. E., and Smith, P. J. (2001). Cyclolysis: A Diagnosis of Two Extratropical Cyclones. Mon. Wea. Rev. 129, 2714-2729. doi:10.1175/1520-0493(2001) $129<2714$ :cadote $>2.0$. co; 2

Nakamura, H. (1993). Horizontal Divergence Associated with Zonally Isolated Jet Streams. J. Atmos. Sci. 50, 2310-2313. doi:10.1175/1520-0469(1993)050<2310: hdawzi> 2.0.co;2

Neiman, P. J., Shapiro, M. A., and Fedor, L. S. (1993). The Life Cycle of an Extratropical marine Cyclone. Part II: Mesoscale Structure and Diagnostics. Mon. Wea. Rev. 121, 2177-2199. doi:10.1175/1520-0493(1993)121<2177: tlcoae $>2.0 . c 0 ; 2$

Neiman, P. J., and Shapiro, M. A. (1993). The Life Cycle of an Extratropical Marine Cyclone. Part I: Frontal-Cyclone Evolution and Thermodynamic Air-Sea Interaction. Mon. Wea. Rev. 121, 2153-2176. doi:10.1175/1520-0493(1993) $121<2153$ :tlcoae $>2.0$. co; 2

Nesterov, E. S. (2010). Explosive Cyclogenesis in the Northeastern Part of the Atlantic Ocean. Russ. Meteorol. Hydrol. 35, 680-686. doi:10.3103/ s1068373910100055

Nuss, W. A., and Kamikawa, S. I. (1990). Dynamics and Boundary Layer Processes in Two Asian Cyclones. Mon. Wea. Rev. 118, 755-771. doi:10.1175/15200493(1990)118<0755:dablpi $>2.0$. co;2

Rausch, R. L. M., and Smith, P. J. (1996). A Diagnosis of a Model-Simulated Explosively Developing Extratropical Cyclone. Mon. Wea. Rev. 124, 875-904. doi:10.1175/1520-0493(1996)124<0875:adoams>2.0.co;2

Reed, R. J., Grell, G. A., and Kuo, Y.-H. (1993a). The ERICA IOP 5 Storm. Part I: Analysis and Simulation. Mon. Wea. Rev. 121, 1577-1594. doi:10.1175/15200493(1993) 121<1577:teispi>2.0.co;2

Reed, R. J., Grell, G. A., and Kuo, Y.-H. (1993b). The ERICA IOP 5 Storm. Part II: Sensitivity Tests and Further Diagnosis Based on Model Output. Mon. Wea. Rev. 121, 1595-1612. doi:10.1175/1520-0493(1993)121<1595: teispi $>2.0 . \operatorname{co} ; 2$

Reed, R. J., Stoelinga, M. T., and Kuo, Y.-H. (1992). A Model-Aided Study of the Origin and Evolution of the Anomalously High Potential Vorticity in the Inner 
Region of a Rapidly Deepening marine Cyclone. Mon. Wea. Rev. 120, 893-913. doi:10.1175/1520-0493(1992)120<0893:amasot>2.0.co;2

Rice, R. B. (1979). Tracking a Killer Storm. Sail 10, 106-107.

Roebber, P. J. (1984). Statistical Analysis and Updated Climatology of Explosive Cyclones. Mon. Wea. Rev. 112, 1577-1589. doi:10.1175/1520-0493(1984) $112<1577$ :saauco $>2.0$. co; 2

Rogers, E., and Bosart, L. F. (1986). An Investigation of Explosively Deepening Oceanic Cyclones. Mon. Wea. Rev. 114, 702-718. doi:10.1175/1520-0493(1986) $114<0702$ :aioedo $>2.0$. co; 2

Sanders, F. (1971). Analytic Solutions of the Nonlinear omega and Vorticity Equations for a Structurally Simple Model of Disturbances in the Baroclinic Westerlies. Mon. Wea. Rev. 99, 393-407. doi:10.1175/1520-0493(1971) 099<0393:asotno >2.3.co;2

Sanders, F. (1986). Explosive Cyclogenesis in the West-Central North Atlantic Ocean, 1981-84. Part I: Composite Structure and Mean Behavior. Mon. Wea. Rev. 114, 1781-1794. doi:10.1175/1520-0493(1986)114<1781:ecitwc $>2.0 . c 0 ; 2$

Sanders, F., and Gyakum, J. R. (1980). Synoptic-Dynamic Climatology of the "Bomb". Mon. Wea. Rev. 108, 1589-1606. doi:10.1175/1520-0493(1980) $108<1589$ :sdcot $>2.0$. co;2

Schemm, S., and Wernli, H. (2014). The Linkage between the Warm and the Cold Conveyor Belts in an Idealized Extratropical Cyclone*. J. Atmos. Sci. 71, 1443-1459. doi:10.1175/jas-d-13-0177.1

Schultz, D. M. (2001). Reexamining the Cold Conveyor belt. Mon. Wea. Rev. 129, 2205-2225. doi:10.1175/1520-0493(2001)129<2205:rtccb >2.0.co;2

Seiler, C., and Zwiers, F. W. (2016a). How Well Do CMIP5 Climate Models Reproduce Explosive Cyclones in the Extratropics of the Northern Hemisphere? Clim. Dyn. 46, 1241-1256. doi:10.1007/s00382-015-2642-x

Seiler, C., and Zwiers, F. W. (2016b). How Will Climate Change Affect Explosive Cyclones in the Extratropics of the Northern Hemisphere? Clim. Dyn. 46, 3633-3644. doi:10.1007/s00382-015-2791-y

Shapiro, R. (1970). Smoothing, Filtering, and Boundary Effects. Rev. Geophys. 8, 359-387. doi:10.1029/rg008i002p00359

Stoelinga, M. T. (1996). A Potential Vorticity-Based Study of the Role of Diabatic Heating and Friction in a Numerically Simulated Baroclinic Cyclone. Mon. Wea. Rev. 124, 849-874. doi:10.1175/1520-0493(1996)124<0849:apvbso >2.0.co;2

Strahl, J. L. S., and Smith, P. J. (2001). A Diagnostic Study of an Explosively Developing Extratropical Cyclone and an Associated 500-hPa Trough Merger. Mon. Wea. Rev. 129, 2310-2328. doi:10.1175/1520-0493(2001)129<2310: adsoae $>2.0 . \mathrm{co} ; 2$

Sun, Y. W., Fu, G., Sun, J. L., and Zhang, S. Q. (2018). Spatial Distribution and Seasonal Variation of Explosive Cyclones over the Northern Atlantic. J. Ocean Univ. China 17 (005), 1000-1010. doi:10.1007/s11802-018-3703-7

Takayabu, I., Niino, H., Yamanaka, M. D., and Fukao, S. (1996). An Observational Study of Cyclogenesis in the lee of the Japan central Mountains. Meteorl. Atmos. Phys. 61, 39-53. doi:10.1007/bf01029710

Uccellini, L. W., Keyser, D., Brill, K. F., and Wash, C. H. (1985). The President's Day Cyclone of 18-19 February 1979: Influence of Upstream Trough Amplification and Associated Tropopause Folding on Rapid Cyclogenesis. Mon. Wea. Rev. 113, 962-988. doi:10.1175/1520-0493(1985)113<0962: tpdcof $>2.0 . \operatorname{co} ; 2$

Uccellini, L. W., Kocin, P. J., Petersen, R. A., Wash, C. H., and Brill, K. F. (1984). The President's Day Cyclone of 18-19 February 1979: Synoptic Overview and Analysis of the Subtropical Jet Streak Influencing the Pre-cyclogenetic Period.
Mon. Wea. Rev. 112, 31-55. doi:10.1175/1520-0493(1984)112<0031: tpdcof $>2.0 . \mathrm{co} ; 2$

Uccellini, L. W., and Kocin, P. J. (1987). The Interaction of Jet Streak Circulations during Heavy Snow Events along the East Coast of the United States. Wea. Forecast. 2, 289-308. doi:10.1175/1520-0434(1987) 002<0289:tiojsc $>2.0$. co; 2

Wakimoto, R. M., Blier, W., and Liu, C. (1992). The Frontal Structure of an Explosive Oceanic Cyclone: Airbone Radar Observations of ERICA IOP 4. Mon. Wea. Rev. 120, 1135-1155. doi:10.1175/1520-0493(1992)120<1135: tfsoae $>2.0 . c 0 ; 2$

Wang, C.-C., and Rogers, J. C. (2001). A Composite Study of Explosive Cyclogenesis in Different Sectors of the North Atlantic. Part I: Cyclone Structure and Evolution. Mon. Wea. Rev. 129, 1481-1499. doi:10.1175/15200493(2001)129<1481:acsoec >2.0.co;2

Warrenfeltz, L. L., and Elsberry, R. L. (1989). Superposition Effects in Rapid Cyclogenesis-Linear Model Studies. J. Atmos. Sci. 46, 789-802. doi:10.1175/ 1520-0469(1989)046<0789:seircm >2.0.co;2

Whitaker, J. S., Uccellini, L. W., and Brill, K. F. (1988). A Model-Based Diagnostic Study of the Rapid Development Phase of the President's Day Cyclone. Mon. Wea. Rev. 116, 2337-2365. doi:10.1175/1520-0493(1988)116<2337: ambdso $>2.0 . c 0 ; 2$

Willison, J., Robinson, W. A., and Lackmann, G. M. (2013). The Importance of Resolving Mesoscale Latent Heating in the North Atlantic Storm Track. J. Atmos. Sci. 70, 2234-2250. doi:10.1175/jas-d-12-0226.1

Yoshida, A., and Asuma, Y. (2004). Structures and Environment of Explosively Developing Extratropical Cyclones in the Northwestern Pacific Region. Mon. Wea. Rev. 132, 1121-1142. doi:10.1175/1520-0493(2004)132<1121: saeoed $>2.0 . \mathrm{co} ; 2$

Zhang, S., Fu, G., Lu, C., and Liu, J. (2017). Characteristics of Explosive Cyclones over the Northern Pacific. J. Appl. Meteorol. Clim. 56, 3187-3210. doi:10.1175/ jamc-d-16-0330.1

Zwack, P., and Okossi, B. (1986). A New Method for Solving the QuasiGeostrophic Omega Equation by Incorporating Surface Pressure Tendency Data. Mon. Wea. Rev. 114, 655-666. doi:10.1175/1520-0493(1986)114<0655: anmfst $>2.0 . \mathrm{co} ; 2$

Conflict of Interest: The authors declare that the research was conducted in the absence of any commercial or financial relationships that could be construed as a potential conflict of interest.

Publisher's Note: All claims expressed in this article are solely those of the authors and do not necessarily represent those of their affiliated organizations, or those of the publisher, the editors and the reviewers. Any product that may be evaluated in this article, or claim that may be made by its manufacturer, is not guaranteed or endorsed by the publisher.

Copyright (c) 2021 Zhang, Liu, Xu, Zhang, Tang, Huang, Zheng, Guan, Mao and Xue. This is an open-access article distributed under the terms of the Creative Commons Attribution License (CC BY). The use, distribution or reproduction in other forums is permitted, provided the original author(s) and the copyright owner(s) are credited and that the original publication in this journal is cited, in accordance with accepted academic practice. No use, distribution or reproduction is permitted which does not comply with these terms. 